\title{
INTEGRAÇ̃̃O ENSINO-SERVIÇO-COMUNIDADE: A EXPERIÊNCIA DA UNIDADE DE SAÚDE ESCOLA ESTRATÉGIA DE SAÚDE DA FAMÍLIA "SÃO FRANCISCO DE ASSIS" NO MUNICÍPIO DE BRAGANÇA PAULISTA / SP. \\ TEACHING-SERVICE-COMMUNITY INTEGRATION: THE EXPERIENCE OF THE HEALTH SCHOOL UNIT FAMILY HEALTH STRATEGY "SÃO FRANCISCO DE ASSIS" IN BRAGANÇA PAULISTA CITY, STATE OF SÃO PAULO.
}

OLIVEIRA, R.M. ${ }^{1}$; LEME, G.V.F.P. ${ }^{2}$; VELOSO, R.V.'; MENESES, E.C. ${ }^{3}$; FERRER, M.L.P. ${ }^{4}$; LEME, L.A.F.P. ${ }^{5}$; TOGNETTI, V.M. ${ }^{5}$, FREIRE, A.C.G.F. ${ }^{5}$; SANTOS, K.L. ${ }^{6}$; OLIVEIRA, V.P. ${ }^{6}$; TERRA, E.M. ${ }^{6}$; NEGRINI, L.D.O. ${ }^{2}$

${ }^{1}$ Curso de Biomedicina; ${ }^{2}$ Curso de Enfermagem; ${ }^{3}$ Curso de Farmácia; ${ }^{4}$ Curso de Fisioterapia;

${ }^{5}$ Curso de Odontologia; ${ }^{6}$ Curso de Medicina - Universidade São Francisco

\section{lisamara.negrini@usf.edu.br}

RESUMO. A integração ensino-serviço-comunidade é entendida como o trabalho coletivo, pactuado e integrado entre estudantes e professores dos cursos da área da saúde e trabalhadores dos serviços de saúde, gestores e comunidade, visando à qualidade da atenção à saúde e da formação profissional, além do desenvolvimento e satisfação dos trabalhadores dos serviços de saúde. O presente artigo de abordagem quanti-qualitativa e método exploratório exibirá as características do processo de implementação da Unidade Escola Estratégia de Saúde da Família "São Francisco de Assis", como também, a opinião da clientela - satisfação dos usuários, discentes e docentes e as potencialidades e desafios do projeto que conta atualmente com 2.646 usuários, os quais são assistidos integralmente por equipe parametrizada de composição híbrida. Entre janeiro e junho de 2017 ofertou 3.620 atendimentos individualizados, além de ações coletivas que contaram com a participação de 183 acadêmicos. Com uma abordagem interdisciplinar, a assistência tem se baseado no acolhimento da demanda espontânea, na prática humanizada, na discussão coletiva dos casos e na continuidade do cuidado, confirmando que a integração ensino-serviço-comunidade apresenta avanços e também muitos desafios, especialmente na compreensão de seu sentido conceitual, cabendo salientar o papel significativo dos gestores municipais neste processo. O presente estudo alcançou seus objetivos e teve sua importância, podendo contribuir para o aprimoramento da integração ESC no SUS, mobilizando iniciativas e novas discussões.

Palavras-chave: Serviços de Integração Docente-Assistencial, Educação Superior, Sistema Único de Saúde.

ABSTRACT. The teaching-service-community integration is understood as the collective
work, agreed and integrated between students and professors of the courses of health area and
workers of health services, managers and community, aiming at the quality of health care and
vocational training, as well as the development and satisfaction of the workers of the health
services. The article of quantitative-qualitative approach and exploratory method will show the
characteristics of the implementation process of the Family Health Strategy - FHS - "São
Francisco de Assis", as well as the opinion of customers - users, students and professors
satisfaction and potentialities and challenges of the project. Currently, there are 2,646 users at
FHS "San Francisco de Assis", who are entirely assisted by a parameterized staff of hybrid
composition (FHS and Municipal Department of Health of Bragança Paulista city, state of Sao
Paulo). Between January and June of 2017 were offered 3.620 individual appointments, as well 
as collective actions which were attended by 183 academics. With an interdisciplinary approach, health care has been based on the reception of spontaneous demand, humanized practice, collective discussion of cases and continuity of care, confirming that the teachingservice-community integration presents advances and also many challenges, especially in understanding its conceptual meaning, emphasizing the significant role of municipal managers in this process. The study reached its objectives and had its importance, to contribute to the improvement of the teaching-service-community integration in the Unified Health System, mobilizing initiatives and new discussions.

Key-words: Professor-Assistencial Integration, College Education, Unified Health System.

\section{INTRODUÇÃO}

Entende-se por integração ensino-serviço-comunidade - ESC o trabalho coletivo, pactuado e integrado entre estudantes e professores dos cursos de formação na área da saúde e trabalhadores que compõem as equipes dos serviços de saúde, incluindo-se os gestores e a comunidade a partir da participação e controle social, visando à qualidade da atenção à saúde individual e coletiva, à qualidade da formação profissional e o desenvolvimento e satisfação dos trabalhadores dos serviços de saúde (ALBUQUERQUE et al, 2008).

Ciente de que o processo de ensinar e aprender nestes novos cenários se forma a partir da integração ESC, que por sua natureza é participativa e de construção coletiva, tendo como eixo central o trabalho cotidiano nos serviços de saúde, a Universidade São Francisco - USF e a Prefeitura Municipal de Bragança Paulista/SP - PMBP, por intermédio de sua Secretaria Municipal de Saúde - SMSa/BP, têm estreitado suas relações nas últimas décadas, proporcionando a inserção efetiva dos alunos em cenários de prática assistencial, ampliando os espaços de integração interinstitucional, assim como proporcionando a qualificação da assistência ofertada.

Tal conjuntura se consolida com a celebração, em agosto de 2016, do Contrato Organizativo de Ação Pública Ensino-Saúde - COAPES $^{1}$, o qual têm suas diretrizes voltadas para o fortalecimento do processo de integração ESC no âmbito do Sistema Único de Saúde SUS, beneficiando o sistema com a inserção multiprofissional dos estudantes - futuros trabalhadores do SUS - cujo aprendizado é direcionado as demandas existentes, assim contribuindo para o aperfeiçoamento e fortalecimento (BRASIL, 2015).

Em 2003, Vilela e Mendes apontaram que a interdisciplinaridade se configura pela capacidade das trocas e pelo grau de integração real das disciplinas no interior de um mesmo projeto. Para os autores, o termo interdisciplinaridade ainda não possui uma definição única e estável. Já Scherer, Pires e Jean (2013) destacaram que a natureza multidimensional do ser humano requer práticas profissionais interdisciplinares que possam conceber "formas mais abrangentes e totalizadoras de aproximar-se da realidade" e que sejam coerentes com os princípios da universalidade, equidade e integralidade da atenção que norteiam o SUS, além de identificar a interdisciplinaridade como um potencial caminho para integrar conhecimento e ação, qualificando o agir, na busca pela integralidade da atenção. Assim, depreendemos que a interdisciplinaridade exige a integração não somente de saberes, mas também de práticas, e

\footnotetext{
${ }^{1}$ Previsto na Lei ${ }^{\circ} 12.871$, de 22 de outubro de 2013, que institui o Programa Mais Médicos, altera as Leis $n^{\circ} 8.745$, de 9 de dezembro de 1993, e $n^{\circ} 6.932$, de 7 de julho de 1981, e dá outras providências, assim como na Resolução $n^{\circ} 03$, de 20 de junho de 2014 que institui as Diretrizes Curriculares Nacionais do Curso de Graduação em Medicina e dá outras providências e na Portaria Interministerial $\mathrm{n}^{\circ}$ 1.127/MEC/MS/2014, que institui as diretrizes para a celebração dos Contratos Organizativos de Ação Pública Ensino-Saúde (COAPES), para o fortalecimento da integração entre ensino, serviços e comunidade no âmbito do Sistema Único de Saúde (SUS).
} 
integra e renormaliza as disciplinas e as profissões delas decorrentes, concretizando, ao final, a íntima relação entre conhecimento e ação.

Neste sentido e a partir do pressuposto de que a Atenção Primária em Saúde - APS é a porta preferencial de acesso ao SUS e a ordenadora do cuidado, USF e a SMSa/BP, implementaram em setembro de 2016, a primeira Unidade Escola - UE de Estratégia de Saúde da Família - ESF da Região de Saúde - RS de Bragança, então denominada "São Francisco de Assis". Localizada no Conjunto Habitacional Marcelo Stefani é consequência do projeto de moradia de interesse social do "Programa Minha Casa Minha Vida", bairro Água Clara do referido município.

A UE "São Francisco de Assis" trata-se de uma das conquistas para o aprimoramento das relações institucionais de integração ESC e atua como cenário de prática para os cursos de graduação de Biomedicina, Enfermagem, Farmácia, Fisioterapia, Medicina e Odontologia, assim como, aos programas de pós-graduação e residência em saúde da USF. Além disso, é considerada equipamento de saúde de fundamental importância para a população adstrita altamente vulnerável - uma vez que reflete a garantia do acesso destes ao SUS. Tal estratégia inovadora proporciona a oferta de serviços, visando atender aos princípios e diretrizes do SUS a partir de uma assistência à saúde de qualidade e que possibilite a melhoria do perfil de saúde da população assistida, bem como um cenário de prática que permita a formação integral dos discentes, com o fortalecimento de suas habilidades e competências.

Assim, considerada a relevância destacada acerca da integração ESC no âmbito do SUS e na formação profissional em saúde, bem como, os desafios para a interdisciplinaridade na Atenção à Saúde é de extrema relevância o compartilhamento de experiências a respeito da temática. Deste modo, o presente artigo objetiva apresentar os esforços da USF e SMSa/BP, a partir da implantação de uma UE ESF "São Francisco de Assis" como ferramenta para o aprimoramento destes processos, visando destacar os caminhos percorridos para a sua implementação, além dos desafios e potencialidades identificadas. Entretanto, é importante destacar que muitos são os desafios para a sua plena operacionalização, sobretudo no que se refere à complexidade do processo saúde doença e a necessidade da abordagem interdisciplinar.

\section{METODOLOGIA}

O método exploratório, com abordagem qualitativa e quantitativa foi utilizado para estruturar o presente estudo de caso, que pretende apresentar o projeto UE ESF "São Francisco de Assis" como ferramenta para o aprimoramento da integração ESC no SUS no município de Bragança Paulista/SP. Para tal, optou-se pela caracterização dos pontos estruturantes do processo, sendo eles: 1. Característica, Organização e Atribuições dos pares - USF e SMSa; 2. Opinião da clientela - Satisfação dos usuários, discentes e docentes; e a 3. Descrição das potencialidades e desafios para uma assistência em saúde, resolutiva e humanizada, pautada na interdisciplinaridade.

\section{RESULTADOS E DISCUSSÃO}

\section{Característica, Organização e Atribuições dos pares}

O processo de implantação da UE ESF "São Francisco de Assis" foi iniciado em 05 de setembro de 2016 e, desde a sua etapa inicial, toda a atenção em saúde tem se baseado na garantia da Universalidade, Equidade e Integralidade do cuidado, princípios doutrinários do SUS, com ações de Promoção de Saúde, Prevenção de Doenças e Assistência à Saúde 
(BRASIL, 1990).

Com a composição hibrida de sua equipe, a UE funciona de segunda a sexta-feira, das 08h00 às 17h00, sendo que os profissionais da SMSa/BP atuam como agentes comunitários de saúde, no apoio ao asseio e como técnicos de enfermagem e administrativo e os profissionais da USF atuam como assistenciais, professores e preceptores de disciplinas dos cursos de graduação de Biomedicina, Enfermagem, Farmácia, Fisioterapia, Medicina e Odontologia, assim como, dos programas de pós graduação e residência em saúde, compondo 01 (uma) equipe parametrizada de $\mathrm{ESF}^{2}$, além de profissionais de apoio, exercendo papel semelhante aos dos Núcleos de Apoio à Saúde da Família - NASF, cujo objetivo central é o de ampliar a abrangência das ações da atenção básica, bem como sua resolubilidade, apoiando a inserção da ESF na rede de serviços e o processo de territorialização e regionalização a partir da Atenção Básica - AB (BRASIL, 2011).

Do ponto de vista estrutural, a UE ESF "São Francisco de Assis" conta com uma infraestrutura física para até 02 (duas) equipes ampliadas de saúde da família, podendo atuar junto a uma população adstrita de até 8 mil usuários de saúde, contém 04 consultórios, sala para os agentes comunitários de saúde, espaço para atividades coletivas, além de áreas técnicas. Todo o fornecimento de equipamentos e mobiliários, bem como, as despesas com insumos, materiais médicos e de enfermagem, medicamentos, comunicação e conectividade são de responsabilidade da SMSa/BP (BRASIL, 2011).

O planejamento e organização do cuidado são responsabilidade da USF, de modo a garantir o atendimento humanizado, acolhedor e livre de qualquer discriminação baseado em uma abordagem interdisciplinar. Para tal, a USF comprometeu-se em concentrar, desde que respeitada a capacidade instalada do serviço, as atividades da residência em saúde, do internato médico e dos estágios supervisionados dos cursos da área da saúde, respeitados os limites de carga horária preconizados nas Diretrizes Curriculares Nacionais do Ministério da Educação DCN/MEC.

Assim, as ações e serviços de saúde foram organizados com base na Política Nacional de Atenção Básica - PNAB visando garantir o cadastramento da população usuária residente no território de abrangência e o atendimento da demanda espontânea e programada, no âmbito a UE e domicílio dos usuários (BRASIL, 2011). Vale destacar que são previstas ações de monitoramento e avaliação acerca da produtividade, qualidade da assistência, além da satisfação dos usuários, discentes e docentes ${ }^{3}$. Atualmente a UE possui 875 famílias cadastradas, totalizando 2.646 cadastros individuais. Observam-se ainda 214 domicílios fechados e 15 recusas para cadastro.

Apresentam-se a seguir as informações de produção de saúde referentes ao período de janeiro a junho de 2017, as quais foram estruturadas, inicialmente de forma global e sequencialmente em áreas específicas. Salienta-se que a verificação da produtividade não tem como objetivo principal, a análise ou verificação do cumprimento de metas estabelecidas e faturamento, processos comumente utilizados no SUS, mas sim, quantificar e apresentar numericamente as possibilidades de atuação oportunizadas aos discentes da USF.

\footnotetext{
${ }^{2}$ Para efeitos de parametrização no Programa Nacional de Melhoria do Acesso e da Qualidade da Atenção Básica (PMAQ) PMAQ, a equipe da ESF ficará condicionada ao seu cadastramento no CNES, agrupando os profissionais de nível superior, de acordo com as seguintes faixas de carga horária: $40 \mathrm{~h}$ de enfermagem, $40 \mathrm{~h}$ de médico e $40 \mathrm{~h}$ de cirurgião dentista. Fonte: Manual Instrutivo para as Equipes de Atenção Básica (Saúde da Família, Saúde Bucal e Equipes Parametrizadas) e Núcleos de Apoio à Saúde da Família (NASF) do Ministério da Saúde (2013).

${ }^{3}$ Os atendimentos realizados no ano de 2016 não serão descritos neste trabalho, tendo em vista que durante este período a equipe esteve empenhada no processo de territorialização, cadastramento da população adstrita e estruturação da unidade instalação gradual de mobiliário e equipamentos, além do atendimento da demanda espontânea dos usuários, considerando se tratar de população vulnerável e que se encontrava descoberta até então.
} 


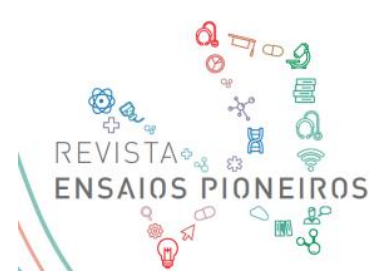

http://ensaiospioneiros.usf.edu.br

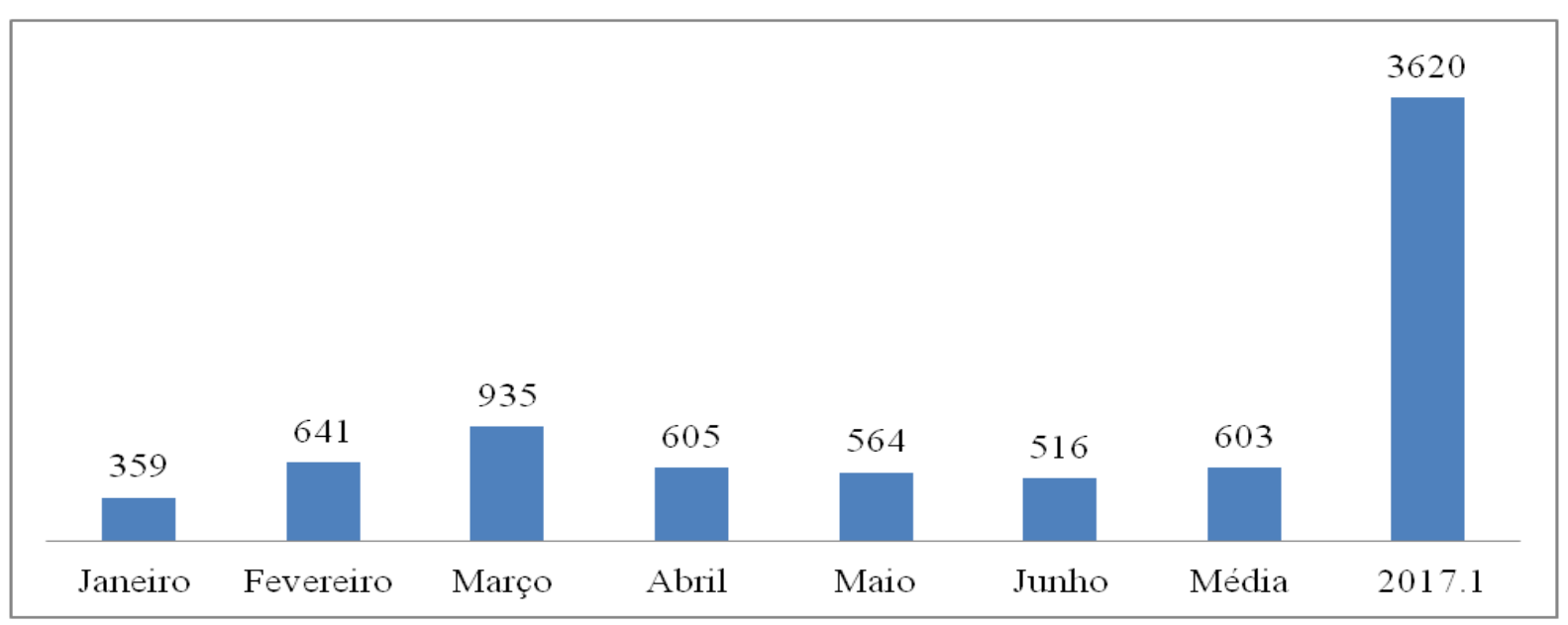

Fonte: Gerenciador de Informações Local - GIL: Coleta Manual.

Figura 01 - Distribuição mensal, semestral e média dos atendimentos individuais realizados pelos discentes sob a supervisão dos professores e preceptores, na UE “São Francisco de Assis", no período de janeiro a junho de 2017.

De acordo com os dados supra apresentados, é possível verificar que ao final do mês de junho de 2017 foram contabilizados 3.620 atendimentos individuais, com uma média mensal de 603 atendimentos. Observa-se ainda que janeiro foi o mês com menor produtividade, justificado pelo período de recesso discente, quando permanecem além da equipe de apoio, apenas 01 profissional médico e 01 profissional enfermeiro em esquema especial de atendimento. Também foi evidenciado um crescimento substancial no número de atendimentos realizados no mês de março, com 935 atendimentos.

Para o cálculo foram incluídos os atendimentos realizados no âmbito da unidade de saúde, assim como, os atendimentos realizados no domicílio dos usuários, durante as visitas domiciliares. Consideram-se atendimentos individuais: as consultas médicas, odontológicas e de enfermagem realizadas pelos profissionais que compões a equipe ampliada, o atendimento fisioterapêutico, psicológico e nutricional, além das coletas de sangue para exames laboratoriais realizadas pelos profissionais que atuam na unidade, conforme formato proposto pelo Ministério da Saúde - MS para os Núcleos de Apoio à Saúde da Família - NASF (BRASIL, 2011). 


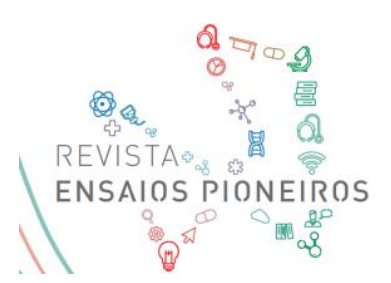

http://ensaiospioneiros.usf.edu.br

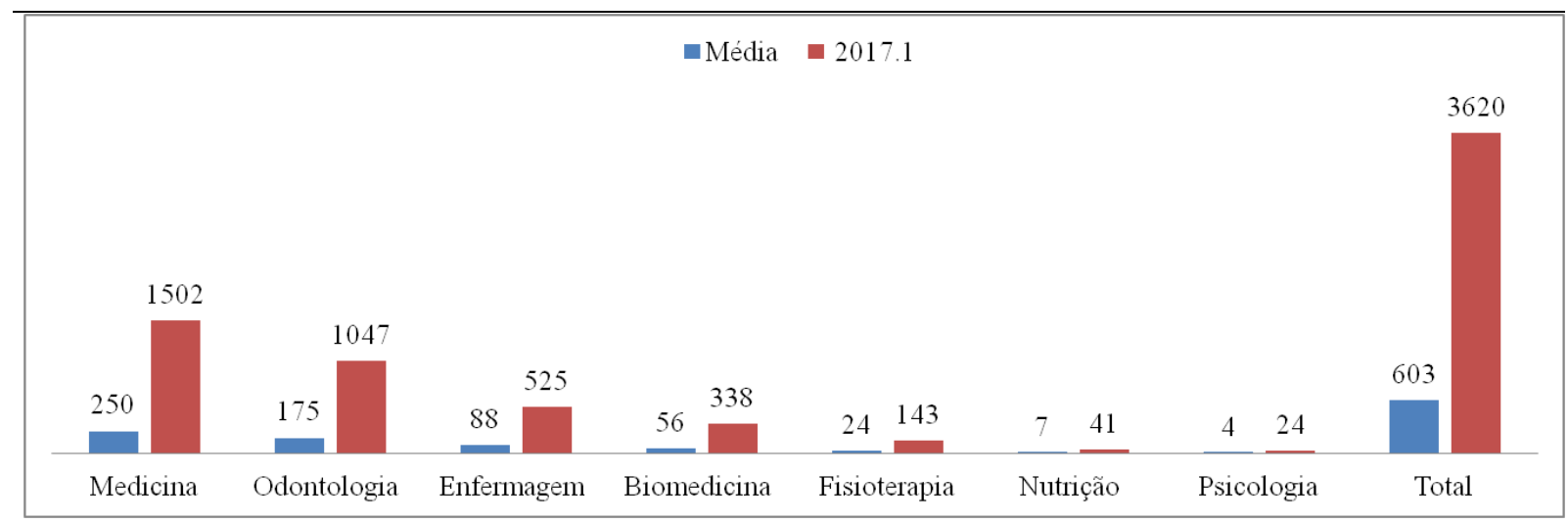

Fonte: Gerenciador de Informações Local - GIL: Coleta Manual.

Figura 02 - Distribuição média dos atendimentos individuais realizados pelos discentes, conforme a área de atuação, sob a supervisão dos professores e preceptores, na UE "São Francisco de Assis", no período de janeiro a junho de 2017.

A análise dos dados acima revela que os discentes do Curso de Medicina realizaram uma média mensal de 250 atendimentos, totalizando ao final do semestre avaliado, 1.502 atendimentos individuais. Dentre os atendimentos individuais, incluem-se: as consultas médicas realizadas no âmbito da unidade de saúde, assim como, as realizadas no domicílio do usuário durante as visitas domiciliares.

Importante destacar que na Atenção Básica, as consultas são distribuídas entre consultas programadas e de demanda espontânea (BRASIL, 2011; BRASIL, 2010). Para a demanda programada, os atendimentos são planejados para atingir toda a família - nas diversas fases do desenvolvimento humano, além de atender as áreas priorizadas pelo Ministério da Saúde em função de sua relevância coletiva - saúde da criança e adolescente, saúde da mulher e gestante, saúde do homem, saúde do idoso, saúde mental - álcool e outras drogas, saúde da pessoa com deficiência, entre outras (BRASIL, 2011).

Já na demanda espontânea, a partir do acolhimento e escuta qualificada, a equipe busca identificar quais são as demandas, questões sociais, para então se definir o tipo de atendimento que o usuário receberá - se será direcionado ou não ao médico e se terá atendimento imediato ou programado (BRASIL, 2010).

Destaca-se também que ao final do período avaliado, contabilizaram-se 525 atendimentos individualizados realizados pelos discentes e residentes de Enfermagem sob a supervisão de professores e preceptores, com uma média mensal de 88 atendimentos individualizados no âmbito da unidade de saúde e no domicílio do usuário de saúde - em visita domiciliar - VD, com atendimentos programados e de demanda espontânea.

Cabe ressaltar que na Atenção Básica, o Enfermeiro não atua exclusivamente na atenção à saúde dos usuários, já que suas atribuições são múltiplas e englobam o desenvolvimento da educação continuada e permanente da equipe, coordenação do trabalho dos Agentes Comunitários de Saúde e Equipe de Enfermagem - planejar, monitorar e avaliar as ações desenvolvidas - além de gerenciar operacionalmente o funcionamento - asseio, manutenção, insumos e equipamentos. Deste modo, além das atividades assistenciais, ora contabilizadas, os discentes e residentes de enfermagem realizam ações de gestão local da unidade, tais como: busca ativa de faltosos, escalas, solicitações, desenvolvimento de ações de educação permanente, entre outras atividades pertinentes (BRASIL, 2011).

Os dados de produção em serviço (Gráfico 2) demonstram ainda que a média mensal de 
atendimentos odontológicos é 175, sendo que no período de janeiro a junho de 2017 foram realizados 1.047 atendimentos individualizados, ressaltando-se que a ausência de produtividade no mês de janeiro se deu em função do recesso acadêmico. Para tanto, a UE ESF "São Francisco de Assis" conta com dois equipos ${ }^{4}$ para o atendimento dos usuários. Para a gestão do acesso, os agendamentos são planejados para garantir o equilíbrio entre primeiras consultas - novos pacientes, retornos - cuidado continuado e demanda espontânea.

Com enfoque na manutenção e melhoria da Saúde Bucal dos usuários, a odontologia na Atenção Básica visa não só o tratamento das doenças, mas prioritariamente a promoção de saúde - hábitos saudáveis e medidas preventivas que permitam a mudança dos paradigmas culturais de que a odontologia se limita a "extração de dentes doentes" (BRASIL, 2011). Além das ações realizadas no âmbito da UE ESF "São Francisco de Assis", no domicílio do usuário - especialmente orientação aos grupos com riscos potencializados - a equipe de Saúde Bucal atua nas escolas do território com ações promotoras de saúde bucal - escovação supervisionada, avaliação e orientação - permitindo aos discentes vivenciar as singularidades da odontologia social.

Também foi possível verificar que, ao final do mês de junho de 2017 , foram totalizados 235 atendimentos individualizados de Fisioterapia, com uma média de 47 atendimentos por mês. O fisioterapeuta atua na saúde da família na atenção integral junto às famílias para a promoção de hábitos saudáveis, na prevenção de doenças e com ações interdisciplinares, visando assistência, acessibilidade e a inclusão social de pessoas portadoras de necessidades especiais ou incapacitadas (CREFITO-3, 2017). Sendo no âmbito da UE ESF "São Francisco de Assis", no domicílio do usuário ou ainda, nas escolas do território, as práticas orientadas permitem aos discentes vivenciar as singularidades sociais e assim preparar o indivíduo para realizar suas atividades de vida diária com maior independência possível e melhor qualidade de vida (CREFITO-3, 2017).

No que se refere as coletas de exames pode-se observar que ao final do período avaliado foram totalizados 338 atendimentos individualizados da Biomedicina, com uma média mensal de 56 atendimentos. Na UE ESF "São Francisco de Assis" os discentes de Biomedicina têm atuado diretamente nas ações de coleta, triagem e resultado dos exames laboratoriais e testes rápidos realizados no local, além do desenvolvimento interdisciplinar de ações preventivas junto à comunidade. Ao Biomédico, cuja regulamentação da profissão se deu pela Lei $\mathrm{n}^{\circ} 6.684$, de 03 de setembro de 1979, compete atuar em equipes de saúde, a nível tecnológico e nas atividades complementares de diagnósticos (BRASIL, 1979). A sua atuação em saúde pública, mais especificamente na APS tem sido apoiada, uma vez que a contribuição funcional e potencial do biomédico inclui a prevenção e promoção da saúde por meio de educação sanitária, coleta e armazenamento de material biológico para análise laboratorial e pesquisa de possíveis agentes etiológicos de maior incidência na comunidade em que atua (BRASIL, 1979).

A análise dos dados também demostrou que, em média, são realizados 07 atendimentos mensais individualizados de nutrição e que ao final do período avaliado foram realizados 41 atendimentos. Os atendimentos nutricionais são realizados no âmbito da UE ESF "São Francisco de Assis", como também durante as visitas domiciliares e são ofertados pelos profissionais que atuam nos programas de residência multiprofissional, sendo eles: Residência Multiprofissional em Saúde Neonatal - RMSN e Residência Multiprofissional em Saúde Intensiva - RMSN, sendo que nesses programas também está prevista atuação na APS e

\footnotetext{
${ }^{4}$ Equipamento no qual são montados e suportados os instrumentos ativos de trabalho do cirurgião dentista, com por exemplo seringa tríplice, alta e baixa rotação, sistema para remoção de placa bacteriana e tártaro, fotopolimerizador, dentre outros, bem como os mecanismos que permitem que estes instrumentos funcionem. Fonte: Anvisa (http://www4.anvisa.gov.br/base/visadoc/REL/REL[8186-2-2].PDF).
} 
Atenção Especializada Hospitalar - AEH. Também participam do programa Residentes psicólogos, os quais realizaram em média 04 atendimentos mensais, totalizando ao final do período analisado 24 atendimentos. Destaca-se as atividades ora descritas se iniciaram somente em março. Vale ressaltar que os atendimentos psicológicos realizados na Unidade Escola são ofertados pelas profissionais que atuam nos programas de residência multiprofissional: RMSN e RMSN. Todas as ações são desenvolvidas interdisciplinarmente e apoiadas na integralidade.

\section{Opinião da clientela - Satisfação dos usuários}

A avaliação tem sido entendida como ferramenta de fundamental importância no planejamento e gestão de serviços e por sua vez traz a visão de julgamento, da prática de intervenções que auxiliam na tomada de decisão, sendo capaz de subsidiar mudanças na construção e/ou na implementação de projetos de saúde e tem como principal objetivo, reordenar a execução das ações e serviços, os redimensionando de forma a contemplar as necessidades de seu público, dando maior racionalidade ao uso dos recursos (CARVALHO, 2012).

Segundo Caldana (2013) um dos principais métodos utilizados na avaliação dos serviços de saúde tem sido a avaliação do usuário, por meio de pesquisas de satisfação, quais são utilizadas para a obtenção de elementos que podem subsidiar as ações voltadas para a melhoria do acesso e qualidade do atendimento prestado e tem se tornado uma ferramenta crítica na construção e consolidação das ações de saúde.

Considerando a importância da avaliação do usuário de saúde SUS, quanto à qualidade do atendimento, numa instituição com integração ESC foi elaborado um instrumento avaliativo sobre a percepção da estrutura, acesso, qualidade de atendimento e campo para observações. $\mathrm{O}$ formulário foi aplicado no período de janeiro até junho de 2017 e a amostra composta por 96 usuários que aceitaram participar da pesquisa. Os dados estão apresentados no Gráfico 3.

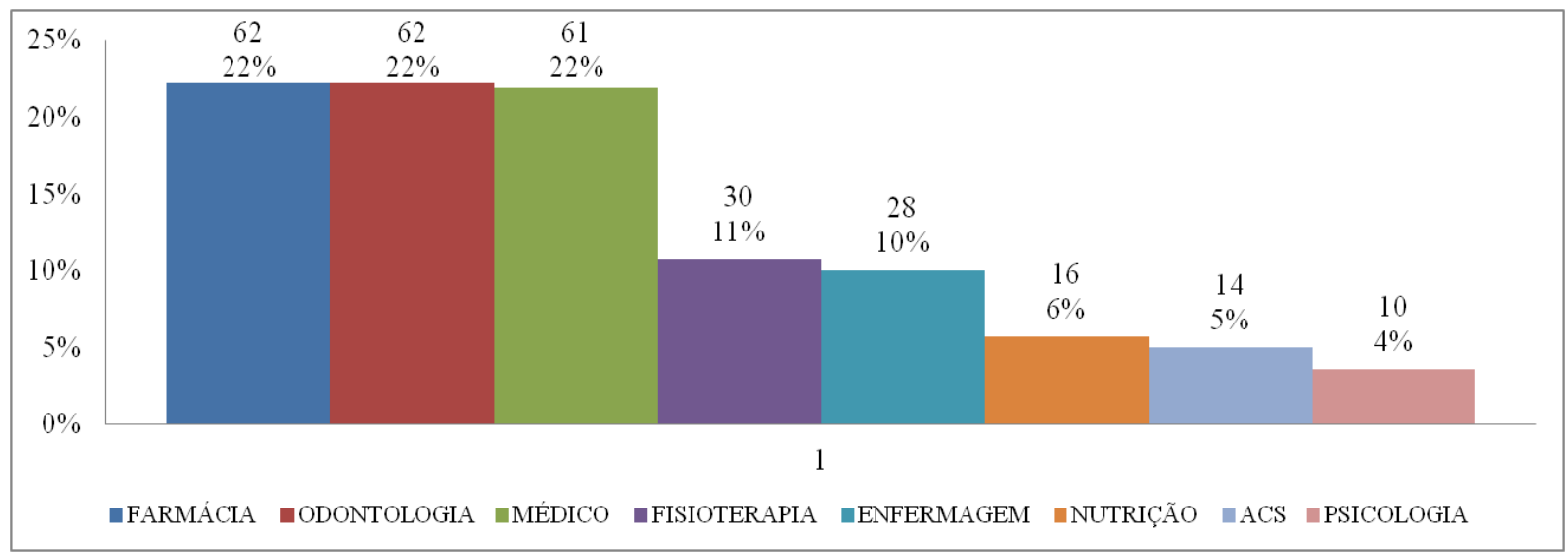

Fonte: Pesquisa de Satisfação.

Figura 03 - Distribuição segundo a procura de atendimentos por áreas específicas, na UE "São Francisco de Assis", no período de janeiro até junho de 2017 (n=96).

A análise dos dados acima revela que os atendimentos médicos e odontológicos, assim como os atendimentos farmacêuticos foram os mais citados dentre os usuários entrevistados. Observa-se ainda que os atendimentos de apoio e atendimentos do agente comunitário de saúde foram os menos citados. 


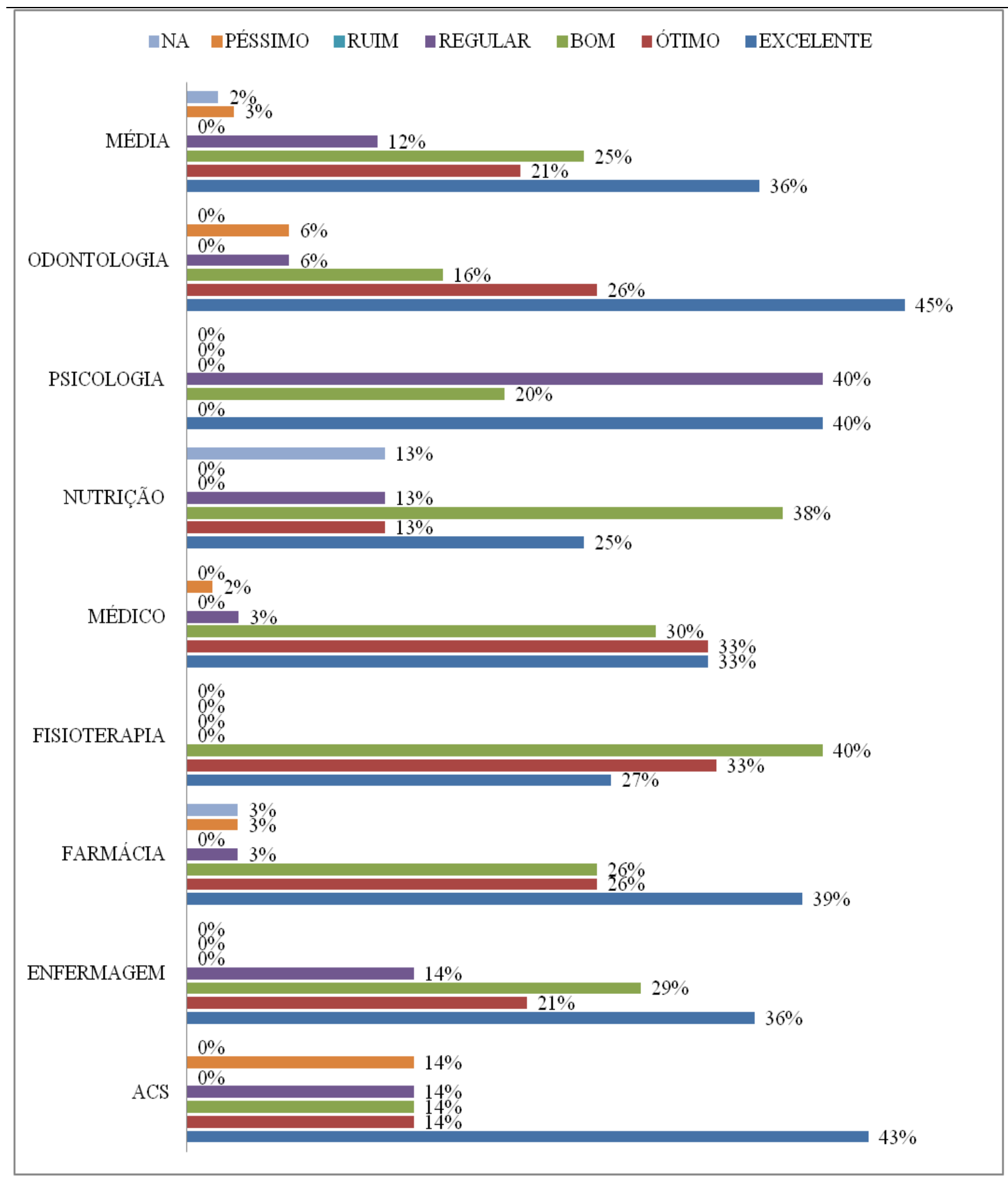

Fonte: Pesquisa de Satisfação.

Figura 04 - Percentual de satisfação dos usuários quanto à qualidade dos atendimentos recebidos na UE "São Francisco de Assis", no período de janeiro a junho de 2017 (n=96).

Os dados supracitados (Figura 4) apresentam o percentual de aprovação dos usuários entrevistados, distribuídos de acordo com as áreas profissionais que prestam atendimento. A média de aprovação foi de $83 \%$, sendo que os atendimentos foram considerados excelentes por $36 \%$ dos entrevistados, ótimos por $21 \%$ e bom por $26 \%$, sendo que os atendimentos de 
Fisioterapia tiveram aprovação de $100 \%$ dos entrevistados. Observa-se ainda que $15 \%$ dos entrevistados consideraram a qualidade dos atendimentos regular, ruim e péssima.

Cotta et al. (2005) apresentaram em sua pesquisa sobre satisfação do usuário na ESF de um município de Minas Gerais, tendo resultados semelhantes ao verificado no presente estudo. Esses autores referem que o grau de satisfação está ligado ao cuidado em saúde ofertado, em especial na relação profissional-usuário, destacando-se o estabelecimento de vínculo e reconhecimento do outro como sujeito protagonista da atenção e do cuidado à saúde, além do acolhimento, tendo como eixo principal a atenção centrada no usuário.

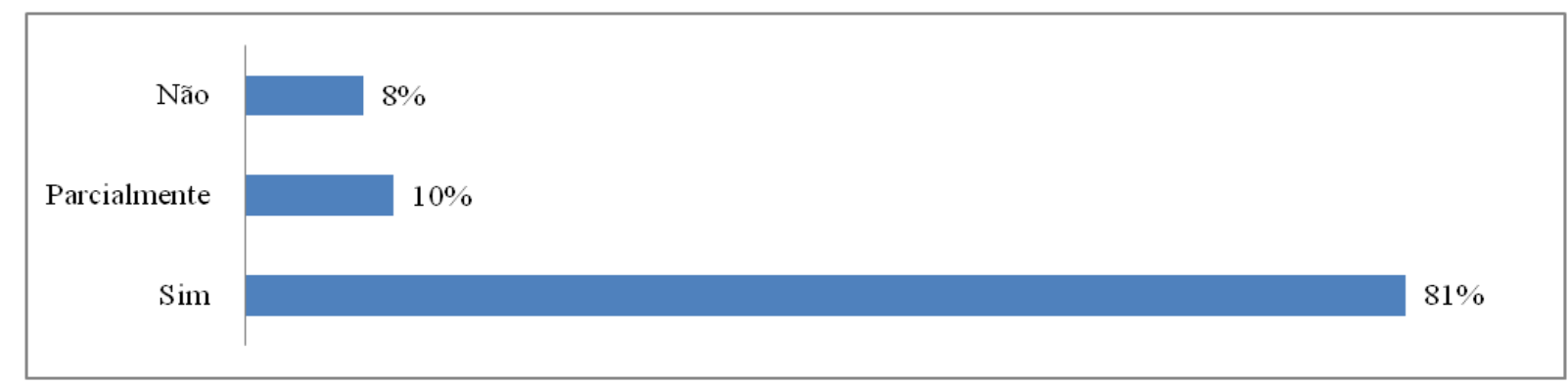

Fonte: Pesquisa de Satisfação.

Figura 05 - Percentual de satisfação dos usuários quanto à resolutividade da equipe frente à demanda dos usuários atendimentos na UE "São Francisco de Assis", no período de janeiro a junho de $2017(\mathrm{n}=96)$.

Com relação ao percentual de resolutividade da equipe da UE "São Francisco de Assis", (Figura 5) 78 usuários entrevistados, o que representa $81 \%$ da amostra, afirmaram ter tido suas necessidades totalmente resolvidas e 10 (10\%) parcialmente resolvidas. Segundo Paim (2015) a APS compõe o primeiro nível de atenção, configurada como porta de entrada ao sistema de saúde, estabelecendo acesso preferencial à população e capaz de resolver mais de $80 \%$ dos problemas de saúde. Assim, sugere-se que a partir da satisfação dos usuários, a UE ESF "São Francisco de Assis" vem conquistando a partir de uma prática humanista e horizontal, a resolutividade da assistência.

\section{Opinião da clientela - Satisfação Discente e Docente}

Segundo Bastas, Brandão e Pinho (1997), a satisfação é o termo utilizado para a expressão do contentamento de um indivíduo com determinada situação, serviço ou grupo de indivíduos. Considera-se satisfeita a pessoa que tem suas expectativas alcançadas, não por um único ponto fixo, mas por uma percepção multidimensional da situação vivenciada.

Assim sendo, numa pesquisa que avalie a satisfação do acadêmico há que se considerar atributos que envolvam o nível de satisfação do estudante com toda a experiência de formação, as instalações e recursos, além da percepção do ambiente acadêmico e intelectual. Com o intuito de mensurar a satisfação dos acadêmicos quanto a integração ensino-serviço, foi elaborado um instrumento avaliativo, com questões objetivas sobre a percepção dos discentes ao que se refere a estrutura, integração das equipes de trabalho e campo para prática, o qual, dentre aproximadamente $183(100 \%)$ acadêmicos, residentes, professores e preceptores que passaram por atividades na UE "São Francisco de Assis”, foi respondido por 64 (35\%), cujos resultados foram destacados nos gráficos a seguir. 


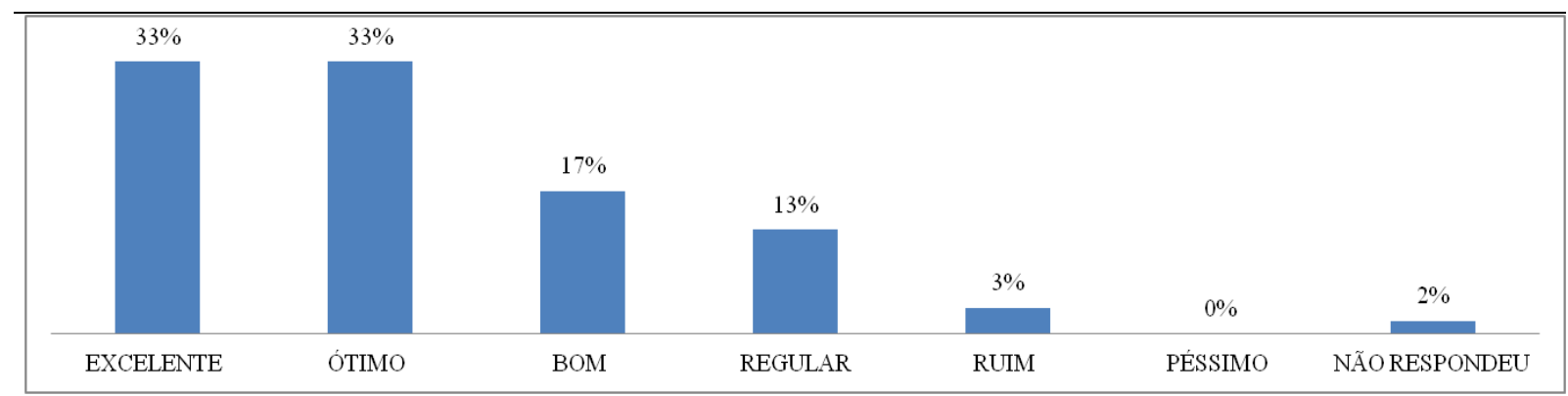

Fonte: Pesquisa de Satisfação.

Figura 06 - Percentual de satisfação dos discentes, residentes, professores e preceptores quanto à qualidade do atendimento ofertado nos balcões de atendimento e recepção da UE "São Francisco de Assis", no período de janeiro a junho de 2017 (n=64).

Os dados supracitados (Figura 6) demonstram o percentual de satisfação quanto à qualidade do atendimento ofertado pela recepção da UE "São Francisco de Assis", sendo verificado um grau elevado de aprovação (53 acadêmicos - 83\%. Vale destacar que dos acadêmicos entrevistados $33 \%$ consideraram o atendimento excelente, sendo 33\% ótimo e 17\% bom. Tal resultado demonstra boa integração e comunicação entre os dos discentes, residentes, professores e preceptores e a recepção da unidade de saúde, o que potencializa a qualidade do atendimento ofertado.

Por outro lado, observou-se que 10 dos entrevistados (16\%) consideraram o atendimento regular e ruim. Tal resultado pode ser complementado com a observação deixada em um dos formulários "Acredito que o atendimento na recepção ficaria excelente se contratasse mais uma profissional", subentendendo-se que a existência de apenas um profissional na recepção seja insuficiente para a demanda de atendimentos existentes, cabendo maiores verificações acerca da questão.

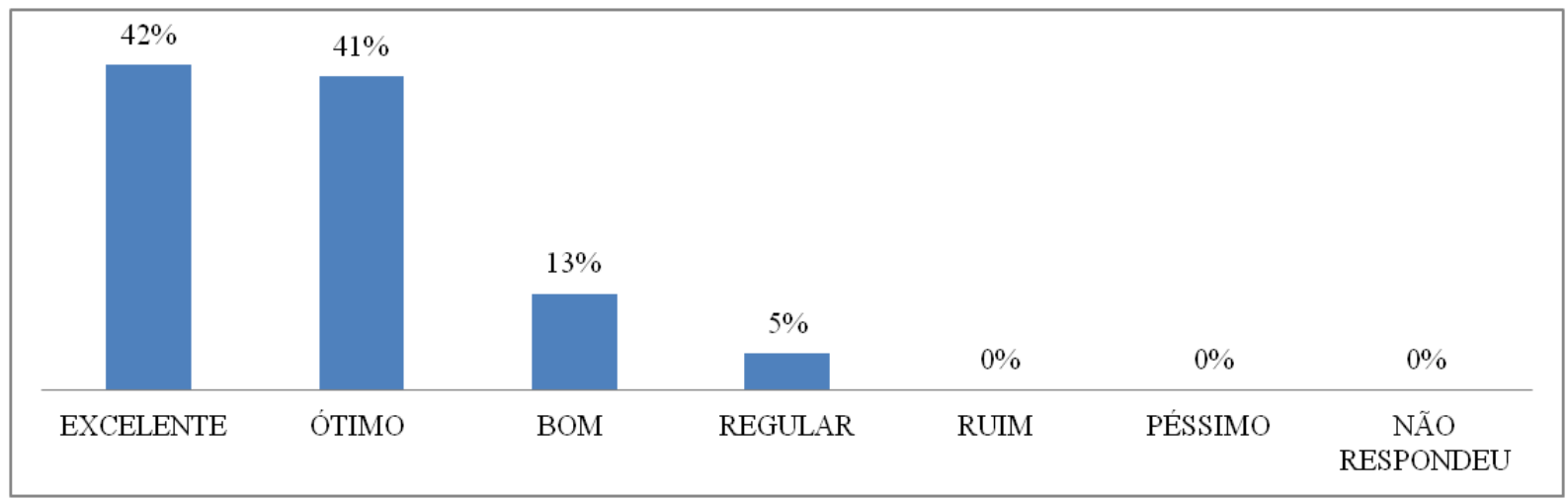

Fonte: Pesquisa de Satisfação.

Figura 07 - Percentual de satisfação dos discentes, residentes, professores e preceptores quanto à qualidade do atendimento de enfermagem e gestão local da UE "São Francisco de Assis", no período de janeiro a junho de 2017 ( $n=64)$.

A análise dos dados (Figura 7) revelou elevado percentual de satisfação dos entrevistados quanto à qualidade do atendimento ofertado pela equipe de enfermagem, demonstrado pelo alto grau elevado de aprovação (61 dos entrevistados - 96\% da amostra), sendo que $42 \%$ dos acadêmicos consideraram o atendimento excelente, $41 \%$ ótimo e $13 \%$ bom. 
Tal resultado demonstra a boa interação das equipes, o que potencializa a qualidade do atendimento ofertado, uma vez que a atuação da enfermagem está diretamente ligada à assistência do paciente, apoio às equipes médicas, organização do fluxo e consultórios, assim como orientação ao usuário após o atendimento médico.

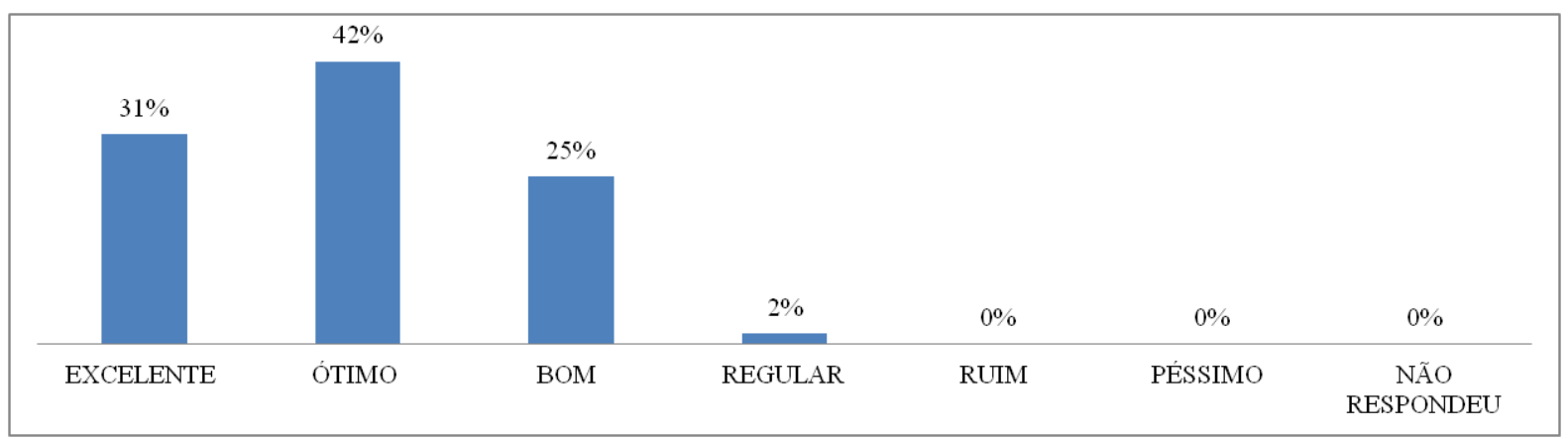

Fonte: Pesquisa de Satisfação.

Figura 08 - Percentual de satisfação dos discentes, residentes, professores e preceptores quanto às possibilidades de aprendizado sobre Sistema Único de Saúde - SUS e sua lógica de atenção, na UE "São Francisco de Assis", no período de janeiro a junho de 2017 (n=64).

Com relação à percepção dos acadêmicos (Figura 8) sobre as possibilidades de aprendizado sobre Sistema Único de Saúde - SUS, os resultados obtidos revelaram elevado percentual de satisfação dos entrevistados, sendo que 63 dos discentes, residentes, professores e preceptores $(98 \%)$ consideraram o cenário de prática excelente $(31 \%)$, ótimo (42\%) e bom $(25 \%)$.

Já com relação à análise qualitativa, os entrevistados teceram diversos elogios à iniciativa, ao ambiente - cenário de prática, ao método utilizado e ao aprendizado alcançado ao final do período. Seguem algumas observações deixadas nos formulários de pesquisa: "Funcionários super atenciosos"; "Apesar de todas as irregularidades estudadas por nós sobre a unidade, a estrutura de atendimento é boa, os pacientes elogiam e se sentem à vontade"; "É sempre mantida muito limpa e higienizada"; "Profissionais atenciosos e integrados uns com os outros"; "A Unidade Escola é um ambiente muito favorável para as práticas do internato, propicia um ambiente acolhedor e que insere o estudante de Medicina a realidade da rede; "Seus desafios e obstáculos, só tenho elogios à unidade e a equipe que a compõe"; "Planejamento, organização de toda equipe, padronização dos prontuários"; Professoras da Odonto da UBS (no coração)!"; "Os professores conduzem com maestria, um atendimento primário de excelência; "Foi um prazer fazer parte dessa dinâmica - Parabéns aos envolvidos!" \#saudecoletivalovers; \#vitorfans; "Turma muito boa de se trabalhar"; "Estão de parabéns". Turma é excelente!"; "Bom relacionamento com a equipe multidisciplinar e realização efetiva das estratégias do MS. Satisfeita com o aprendizado que obtive nesta unidade"; "Obtive ótimas experiências de aprendizado no local, o ESF cumpre os requisitos e pressupostos de atendimento, referência, contra-referência e acolhimento". "Foi um estágio muito rico".

Potencialidades e Desafios para uma assistência em saúde, resolutiva e humanizada, pautada na interdisciplinaridade 
Com base na Lei de Diretrizes e Bases da Educação Nacional (LDB) ${ }^{5}$, que assegura ao Ensino Superior maior flexibilidade na organização curricular dos cursos, o currículo mínimo de cada curso foi substituído por um novo instrumento: as Diretrizes Curriculares Nacionais (DCN). As DCN têm, como linhas gerais, o estabelecimento do perfil profissional para cada área, o conjunto de competências e o rol de conteúdos que deverão ser ministrados (MEC, 1996). Em comum espera-se que os profissionais da saúde possuam uma formação generalista, humanista, crítica e reflexiva, sendo capacitados a atuar, com base em princípios éticos, no processo de saúde-doença em seus diferentes níveis de atenção, com ações de promoção, prevenção, recuperação e reabilitação à saúde, e na perspectiva da integralidade da assistência, com senso de responsabilidade social e compromisso com a cidadania (MEC, 1996).

Para Fleury e Fleury (2001) mais do que estabelecer competências, o grande desafio é o de torná-las condutas de rotina. O conceito de competência envolve três dimensões: o conhecimento, a habilidade e a atitude. Entende-se, portanto, que as competências não estão desarticuladas do desempenho esperado e que este implica o agir. Por sua vez, em 2011, os documentos "Universidade Aberta do Sistema Único de Saúde" esclarecem que o fazer em saúde, fruto do saber e da habilidade, determina resultados específicos. Assim, a mudança efetiva que se pretende no modelo assistencial de nossas práticas, a partir da lógica da ESF, só se dará a partir de um contínuo repensar entre teorias, práticas e ações em saúde.

Neste sentido, as ações em saúde devem visar o resgate das condições que a pessoa ou grupo social julgarem adequadas. Na Atenção Básica, as tecnologias de saúde que produzem o cuidado são aquelas consideradas leve (os modos relacionais de agir na produção dos atos de saúde) e leve-duro (os saberes tecnológicos clínicos e epidemiológicos) e, independentemente do recorte profissional, todos os trabalhadores da área fazem clínica cuidadora e operam práticas sanitárias (NOGUEIRA, 2009).

Outra habilidade, além da prática sanitária, é a de planejar ações. Durante os cursos de graduação em saúde há maior direcionamento para a prestação da assistência individual e para o seguimento de protocolos. É preciso criar espaços e oportunidades de discussão para o treinamento das habilidades de liderança, de articulação do trabalho em equipe, de comunicação e de intervenção nas necessidades de saúde além das práticas curativas (LOURENÇÃ̃); BENITO, 2010).

Segundo Machado (2004), para a melhor articulação do trabalho em equipe, devemos pensar na interdisciplinaridade. Não basta ter conhecimento técnico e habilidade se isso não resultar em atitudes coerentes com o que se espera de uma ESF. Este autor ainda refere que cada ser humano pode ser caracterizado por um amplo espectro de habilidades, de competências, associadas à ideia de uma inteligência individual, entendida como uma capacidade de ter vontades, de estabelecer metas, de criar, de sonhar e de ter projetos. Em termos coletivos, a diversidade também é a regra e a norma de saber lidar com as diferenças.

Machado (2004) salienta ainda que a ideia de tolerância, embora não se configure como uma competência pode influenciar na postura do profissional e facilitar o relacionamento entre a ESF, pois se resume no respeito ao outro como diferente de mim, sem procurar dissolvê-lo em minhas análises, situá-lo em meu cenário, traduzi-lo em minha linguagem. Trata-se de valorizar suas perspectivas, de reconhecer a existência de cenários diferentes do meu, de colocar-me em disponibilidade para comunicar-me com ele, ainda que continuemos a falar línguas diferentes e a alimentar projetos diferentes. A tolerância exige, portanto, conhecimento, compreensão e reconhecimento do outro como outro.

Consideradas as perspectivas balizadas na literatura, a busca por transformação na

\footnotetext{
5 Lei no 9.394, de 20 de dezembro de 1996, que estabelece as diretrizes e bases da educação nacional.
} 
formação do profissional de saúde tem sido um desafio, sobretudo na UE "São Francisco de Assis", quando diferentes atores, de diferentes etapas de formação e profissão, configuram a equipe de saúde. No entanto, muitos têm sido os esforços para que o indivíduo seja habilitado não somente para a prática sanitária, mas também hábil na liderança e articulação de comunidades e processos, especialmente no que tange a integralidade e as mudanças de paradigmas, quanto ao cuidado de saúde.

Para Merhy (2004), um modelo que se deseja pautar pela necessidade do usuário/família deve sair da lógica do consumo em saúde, desafiando os diversos atores a analisar a situação e protagonizar as ações que gerem novos sentidos para a produção dos atos de cuidar. Destacase ainda, o entendimento do autor sobre o acolhimento como principal proposta para a mudança no modelo de organização da assistência e do processo de trabalho em saúde. Nesse contexto, acolher significa dar atenção em todas as suas dimensões (física, psicológica, social e espiritual), ouvi-lo, valorizar suas queixas, identificar suas necessidades, incluir a família no atendimento e tentar informar o paciente e a família sobre todas as possibilidades de tratamento. Com o acolhimento, estabelecemos vínculo com o paciente e sua família, o que facilita a criação de uma relação humanizada. Ao acolher um paciente, a equipe de saúde manifesta sua responsabilidade perante ele e seu tratamento (MERHY, 2004).

Na UE ESF "São Francisco de Assis" a prática do acolhimento frente à demanda espontânea e programada vem acontecendo de forma interdisciplinar, com a participação de discentes dos variados cursos da saúde que atuam na ESF, sempre acompanhados pelo preceptor. Para tal, tem se buscado uma abordagem humanista, que permita desenvolver a escuta qualificada e a responsabilização da equipe sobre as possibilidades de tratamento, estabelecendo assim o vínculo entre paciente/equipe.

Dentre as atribuições dos profissionais da equipe atuante na ESF, destaca-se o trabalho multiprofissional e interdisciplinar, o qual deve contribuir na gestão do cuidado integral do usuário. Deste modo, ocorre a soma de saberes para que possam se concretizar em cuidados efetivos dirigidos à população de um território definido, pelo qual esta equipe assume responsabilidade (BRASIL, 2011).

As visitas domiciliares (VD) tem se demonstrado uma experiência e oportunidade de partilhar em caráter interdisciplinar, com o olhar acadêmico e profissional, a integralidade do cuidado. Essas práticas são pautadas na coordenação das ações de prevenção, promoção, reabilitação e educação em saúde, bem como a longitudinalidade da assistência prestada e garantia do acesso aos serviços de saúde ofertados. A participação das famílias envolvidas, com incentivo para uma decisão partilhada e realista são constantemente incentivadas, respeitando as competências culturais e comunitárias envolvidas, sempre com o olhar na melhoria da atenção prestada, dos recursos utilizados e resolutividade dos instrumentos e atitudes empregados (ARAÚJO; ROCHA, 2007).

Na UE ESF “São Francisco de Assis” as VD acontecem semanalmente, após reunião de equipe para discussão dos casos individuais e familiares que serão visitados por todos os cursos participantes (Medicina, Fisioterapia, Enfermagem, Biomedicina e Farmácia), elaborando em conjunto as estratégias e atitudes que serão aplicados durante a ação domiciliar. Após a realização das visitações é realizado um fechamento conjunto com a equipe de saúde, docentes e discentes envolvidos no cenário para elaboração de linhas de cuidados e projetos terapêuticos singulares (BRASIL, 2014).

Quando um grupo trabalha de forma interdisciplinar, discussões que levem ao diagnóstico do paciente até as intervenções de terapêutica são debatidas por todos os profissionais envolvidos, o que facilita a definição de objetivos e a linguagem comum da equipe. Para tanto, é necessário que os profissionais se organizem através de reuniões de 
planejamento e avaliação, com troca de informação e experiência, respeitando, reconhecendo e incorporando as experiências individuais dentro de um processo colaborativo e integrado (PIMAZONI-NETTO; RODBARD; ZANELLA, 2011).

Pode-se citar, além das reuniões programadas da equipe de saúde, reuniões extraordinárias em caráter organizativo, frente às demandas operacionais das disciplinas e da unidade, a partir do olhar integrador, ocorrem com frequência e buscam dar suporte gerencial à equipe na construção e desenvolvimento dos processos de trabalho.

Neste contexto, como proposta de trabalho interdisciplinar dentro da UE ESF "São Francisco de Assis", destacam-se as reuniões clínicas das áreas de Medicina e Biomedicina para discussão de resultados dos exames laboratoriais. Os discentes, seus preceptores e integrantes da equipe de saúde se reúnem quinzenalmente para discutir os principais achados laboratoriais de relevância clínica, propondo estratégias de intervenção para a promoção da saúde, prevenção de doença e conduta terapêutica, fazendo deste momento um importante espaço para aprimoramento do processo formativo através da troca e construção compartilhada de saberes, do reconhecimento da atividade do outro e do cuidado adequado ao paciente.

Dentre outras atividades desenvolvidas frente à perspectiva de provocar, planejar, desenvolver e analisar a integração pode-se citar o desenvolvimento de trabalhos discentes no espaço da unidade e seu território, bem como, a atuação e intervenção pontual através do desenvolvimento de projetos das diferentes disciplinas dos diversos cursos que utilizam o cenário como espaço de ensino e aprendizagem. Como exemplo do curso de Medicina podemos citar as atuações e intervenções desenvolvidas pelas disciplinas da área de Saúde Coletiva, do $1^{\circ}$ ao $9^{\circ}$ semestre, considerando neste último, o internato em Saúde Coletiva, estágio em que desenvolvemos uma atividade denominada Trabalho de Desenvolvimento em Campo (TDC) na qual os alunos propõem, através da construção conjunta com os demais integrantes da equipe, a elaboração de protocolos assistenciais ajustados à realidade do nível primário de atenção, a identificação de potencialidades e fragilidades do processo de trabalho e das vivências e interfaces existentes entre os diferentes atores.

Outro aspecto a ser considerando tem sido a prática multiprofissional e interdisciplinar desenvolvida na UE ESF "São Francisco de Assis" para o acompanhamento das atividades de saúde pública, com ações em gestão, monitoramento e acompanhamento de prioridades em saúde, além da Clínica Ampliada com atendimento compartilhado e apoio matricial para a equipe de referência, discussão de projeto terapêutico singular em equipe e de microrregulação na rede de atenção à saúde, a exemplo dos cursos de Fisioterapia e Medicina (FERRER et al., 2013).

As particularidades da profissão do Farmacêutico requerem formas abrangentes de aproximação da realidade, assim, o desenvolvimento da relação entre conhecimento e ação são essenciais. Na UE ESF “São Francisco de Assis” os discentes do Curso de Farmácia realizaram sob supervisão: $1^{\circ}$ ) Acolhimento dos pacientes com suas receitas procedendo à escuta qualificada; $2^{\circ}$ ) Identificação das necessidades e os problemas de saúde do paciente avaliando o risco e vulnerabilidade do mesmo através da avaliação da farmacoterapia, considerando a necessidade, o acesso, a efetividade, a segurança e a comodidade, bem como os aspectos legais e técnicos da prescrição da própria unidade ou de prescrições exógenas; $3^{\circ}$ ) Avaliação de experiências prévias nos processos de uso do medicamento e itinerários terapêuticos dos pacientes bem como eventos adversos relacionados aos mesmos; $4^{\circ}$ ) Comunicação de forma efetiva ao paciente, e quando pertinente ao cuidador, à família e aos profissionais da unidade, das necessidades e os problemas de saúde do paciente; $5^{\circ}$ ) Elaboração de planos de cuidado definindo, em consonância com as políticas públicas de saúde; $6^{\circ}$ ) Construção de planos de cuidado pactuado com o paciente e articulado com a equipe de saúde multiprofissional de saúde 
da unidade; $7^{\circ}$ ) Contribuição e/ou participação para a tomada de decisão da equipe multiprofissional sobre a farmacoterapia; $8^{\circ}$ ) Realização de intervenções estabelecidas no plano de cuidado junto à equipe multiprofissional; $9^{\circ}$ ) Monitorização terapêutica de medicamentos e conciliação de medicamentos; $10^{\circ}$ ) Adequação da prescrição à rotina do paciente (aprazamento), orientações e/ou organização dos medicamentos através de caixas organizadoras de medicamentos em pacientes polimedicados e $11^{\circ}$ ) Avaliação dos resultados das intervenções realizadas. Portanto a unidade tem se constituído num cenário de prática diferenciado de ensino e aprendizagem multiprofissional, que vem desenvolvendo atividades relacionadas aos medicamentos industrializados, previsto no Projeto Pedagógico do Curso, tendo caráter formador, inovador e comprometido com a ética e a qualidade da educação farmacêutica.

A gestão local da UE tem sido desenvolvida pelo Curso de Enfermagem e para a qual tem se buscado uma abordagem horizontalizada e democrática, envolvendo os discentes das diversas áreas e com vistas para uma nova prática que possibilite criar condições para o direcionamento do processo de trabalho e o desenvolvimento de serviços, na busca de qualidade e do impacto das suas ações sobre a realidade da comunidade. Na reorientação das práticas enfatiza-se a ação com base na necessidade da comunidade - aplicando os recursos na busca da melhoria da cobertura, da resolutividade, da satisfação da clientela e incentivando e fomentando melhorias nas relações interpessoais.

\section{CONCLUSÃO}

O presente estudo permitiu apresentar os esforços da USF e SMSa/BP para o aprimoramento da integração ESC a partir da experiência da UE ESF "São Francisco de Assis", a qual se baseia e consolida pelo compromisso dos pares, desejo de transformação e refinamento do ensino em saúde, como também pela participação popular - envolvida e valorizada - em todo o processo cujo início se deu em 2016.

Ao pontuar os mais de 3600 atendimentos ofertados entre janeiro e junho de 2017 evidenciam-se, além do acesso oportunizado à população para a ATS no SUS municipal, as inúmeras oportunidades de aprendizado prático aos mais de 180 acadêmicos participantes do projeto no período. Tais evidências confirmam que a integração ESC vem apresentando avanços e também muitos desafios, especialmente no que tange a compreensão de seu sentido amplo e a sua relevância nos processos de inovação na formação profissional e na atenção à saúde da população.

Os desafios identificados se curvam aos avanços conquistados em tão ínfimo período, no qual se conquistou não só a total implantação da infraestrutura, comunicação e conectividade, como o cadastramento e delineamento do território de abrangência. Outro ponto de destaque se dá ao protagonismo dos profissionais frente à humanização do atendimento, o cuidado continuado e a abordagem interdisciplinar, com o envolvimento constante e intenso dos acadêmicos na prática assistencial e de liderança e articulação em equipes, de forma a originar egressos com competências e habilidades para produção de uma prática de saúde de qualidade e fundamentada nos princípios e diretrizes do SUS.

É sabido que há muito que se evoluir, no entanto, os passos preliminares já foram dados, cabendo salientar o papel significativo dos gestores municipais neste processo, contribuindo fortemente para a sua rápida evolução, como a sua estagnação quando não apropriado da questão. Assim, conclui-se que o presente estudo alcançou seus objetivos e teve sua importância, podendo contribuir para o aprimoramento da integração ESC no SUS, mobilizando iniciativas e novas discussões acerca da temática. 


\section{REFERÊNCIAS}

ALBUQUERQUE, Verônica Santos et al. A integração ensino-serviço no contexto dos processos de mudança na formação superior dos profissionais da saúde. Rev. bras. educ. med., Rio de Janeiro, v. 32, n. 3, p. 356-362, Sept. 2008. Disponível em $<$ http://www.scielo.br/scielo.php?script=sci_arttext\&pid=S0100$55022008000300010 \& \operatorname{lng}=\mathrm{en} \& n r m=$ iso>. Acesso em 03 Nov. 2017.

ARAUJO, Marize Barros de Souza; ROCHA, Paulo de Medeiros. Trabalho em equipe: um desafio para a consolidação da estratégia de saúde da família. Ciênc. saúde coletiva, Rio de Janeiro, v. 12, n. 2, p. 455-464, Apr. 2007. Disponível em $<$ http://www.scielo.br/scielo.php?script=sci_arttext\&pid=S1413$81232007000200022 \& \operatorname{lng}=$ en\&nrm=iso>. Acesso em 03 Nov. 2017.

BASTOS, Antonio Virgílio B; BRANDAO, Margarida G. A; PINHO, Ana Paula M. Comprometimento organizacional: uma análise do conceito expresso por servidores universitários no cotidiano de trabalho. Rev. adm. contemp., Curitiba, v. 1, n. 2, p. 97-120, Aug. 1997. Disponível em <http://www.scielo.br/scielo.php?script=sci_arttext\&pid=S1415$65551997000200006 \& \operatorname{lng}=\mathrm{en} \& n r m=$ iso $>$. Acesso em 10 Nov. 2017.

BRASIL. Lei no 6.684, de 03 de setembro de 1979. Brasília, 1979. Disponível em <http://www.planalto.gov.br/ccivil_03/leis/1970-1979/L6684.htm>. Acesso em 02 Nov. 2017.

BRASIL. Lei no 8080, de 19 de setembro de 1990. Brasília, 1990. Disponível em <https://www.planalto.gov.br/ccivil_03/LEIS/L8080.htm> Acesso em 05 Nov. 2017.

BRASIL. Lei n. 9.394, de 20 de dezembro de 1996. Brasília: 1996. Disponível em <http://www.planalto.gov.br/ccivil_03/leis/L9394.htm>. Acesso em 02 Nov. 2017.

BRASIL. Ministério da Saúde. Secretaria de Gestão do Trabalho e da Educação na Saúde. Universidade Aberta do Sistema Único de Saúde. Competências dos profissionais de nível superior na estratégia de saúde da família / Universidade Aberta do Sistema Único de Saúde. Brasília: UNA-SUS, 2011. Disponível em <https://www.unasus.gov.br/node/381>. Acesso em 20 Nov. 2017.

BRASIL. Ministério da Saúde. Portaria no 2.488, de 21 de outubro de 2011. Brasília, 2011. Disponível em <https://www.nescon.medicina.ufmg.br/cgibin/wxis/?IsisScript=ceabsf_print.xis\&search_list=0000002968>. Acesso em 03 Nov. 2017.

BRASIL. Ministério da Saúde. Acolhimento à demanda espontânea: queixas mais comuns na Atenção Básica. Brasília, 2012. Disponível em $<$ http://bvsms.saude.gov.br/bvs/publicacoes/acolhimento_demanda_espontanea_cab28v1.pdf >. Acesso em 03 Nov. 2017.

BRASIL. Ministério da Saúde. Programa nacional de melhoria do acesso e da qualidade da atenção básica (PMAQ): manual instrutivo. Brasília: Ministério da Saúde, 2013. Disponível em <http://dab.saude.gov.br/portaldab/biblioteca.php?conteudo=publicacoes/pmaq > . Acesso em 
05 Nov. 2017.

BRASIL. Ministério da Saúde. Núcleo de Apoio à Saúde da Família. v. 1. Brasília: Ministério da Saúde, 2014. (Cadernos de Atenção Básica, n. 39). Disponível em http://dab.saude.gov.br/portaldab/biblioteca.php?conteudo=publicacoes/cab39. Acesso em 01 de dezembro 2017.

BRASIL. Ministério da Educação. Ministério da Saúde. Portaria no 1.127, de 04 de agosto de 2015. Brasília, 2015. Disponível em <http://portalarquivos.saude.gov.br/images/pdf/2015/outubro/23/COAPES-PORTARIAINTERMINISTERIAL-N1.127\%20-DE-04\%20DE-AGOSTO-DE-2015.pdf > . Acesso em 04 Nov. 2017.

CALDANA, Graziela et al. Avaliação da qualidade de cuidados de enfermagem em hospital privado. Revista Eletrônica de Enfermagem, Goiânia, v. 15, n. 4, p. 915-22, dez. 2013. ISSN 1518-1944. Disponível em: 〈https://revistas.ufg.br/fen/article/view/19655>. Acesso em 20 Nov. 2017.

CARVALHO, André Luis Bonifácio de et al. A gestão do SUS e as práticas de monitoramento e avaliação: possibilidades e desafios para a construção de uma agenda estratégica. Ciênc. saúde coletiva, Rio de Janeiro, v. 17, n. 4, p. 901-911, Apr. 2012. Disponível em <http://www.scielo.br/scielo.php?script=sci_arttext\&pid=S1413$81232012000400012 \& \operatorname{lng}=$ en\&nrm=iso>. Acesso em 29 Nov. 2017.

CONSELHO REGIONAL DE FISIOTERAPIA E TERAPIA OCUPACIONAL $3^{\text {a }}$ REGIÃO. Tudo o que o gestor deve saber sobre fisioterapia e como implantá-la em seu município. Disponível em < http://www.crefito3.org.br/dsn/pdfs/Cartilha\%20-\%20fisioterapeuta.pdf $>$ Acesso em 03 Nov. 2017.

COTTA, R.M.M. A satisfação dos usuários do Programa de Saúde da Família: avaliando o cuidado em saúde. Sci. med., v. 15 n. 4, p.227-234, 2005. Disponível em

<http://revistaseletronicas.pucrs.br/ojs/index.php/scientiamedica/article/viewDownloadIntersti tial/1572/7927>. Acesso em 02 Nov. 2017.

FERRER, M.L. P et al. Microrregulação do acesso à rede de atenção em fisioterapia: estratégias para a melhoria do fluxo de atendimento em um serviço de atenção secundária. Fisioter. Pesqui., São Paulo, v. 22, n. 3, p. 223-230, Sept. 2015. Disponível em $<$ http://www.scielo.br/scielo.php?script=sci_arttext\&pid=S180929502015000300223\&lng=en\&nrm=iso>. access on 04 Dec. 2017.

FLEURY, Maria Tereza Leme; FLEURY, Afonso. Construindo o conceito de competência. Rev. adm. contemp., Curitiba, v. 5, n. spe, p. 183-196, 2001. Disponível em $<$ http://www.scielo.br/scielo.php?script=sci_arttext\&pid=S1415$65552001000500010 \& \operatorname{lng}=\mathrm{en} \& n \mathrm{~nm}=\mathrm{iso}>$. Accesso em 30 Nov. 2017.

LOURENÇAO, Daniela Campos de Andrade; BENITO, Gladys Amélia Véles. Competências gerenciais na formação do enfermeiro. Rev. bras. enferm., Brasília, v. 63, n. 1, p. 91-97, Feb. 2010. Disponível em <http://www.scielo.br/scielo.php?script=sci_arttext\&pid=S0034- 
$71672010000100015 \& \operatorname{lng}=$ en\&nrm=iso $>$. Acesso em 30 Nov. 2017.

MACHADO, Nilson José. Projetos e valores. 5 ed. São Paulo: Escrituras Editora, 2004.

MERHY, Emerson Elias et al. O trabalho em saúde: olhando e experienciando o SUS no cotidiano. 2 ed. São Paulo: Hucitec, 2004.

NOGUEIRA, Maria Inês. As mudanças na educação médica brasileira em perspectiva: reflexões sobre a emergência de um novo estilo de pensamento. Rev. bras. educ. med., Rio de Janeiro, v. 33, n. 2, p. 262-270, June 2009. Disponível em $<$ http://www.scielo.br/scielo.php?script=sci_arttext\&pid=S0100$55022009000200014 \& \operatorname{lng}=$ en\&nrm=iso>. Acesso em 30 Nov. 2017.

PAIM, J. S. O que é o SUS. Rio de Janeiro: Fiocruz, 2015. E-book. Disponível em: <http://www.livrosinterativoseditora.fiocruz.br/sus/>. Acesso em: 21 abr. 2017.

PIMAZONI-NETTO, Augusto; RODBARD, David; ZANELLA, Maria Tereza. Rapid Improvement of Glycemic Control in Type 2 Diabetes Using Weekly Intensive Multifactorial Interventions: Structured Glucose Monitoring, Patient Education, and Adjustment of Therapy - A Randomized Controlled Trial. Diabetes TechnolTher, v. 13, n. 10, p. 997-1004, out. 2011. Disponível em <https://doi.org/10.1089/dia.2011.0054>. Acesso em 19 Nov 2017.

SCHERER, Magda Duarte dos Anjos; PIRES, Denise Elvira Pires de; JEAN, Rémy. A construção da interdisciplinaridade no trabalho da Equipe de Saúde da Família. Ciênc. saúde coletiva, Rio de Janeiro, v. 18, n. 11, p. 3203-3212, Nov. 2013. Disponível em $<$ http://www.scielo.br/scielo.php?script=sci_arttext\&pid=S1413$81232013001100011 \& \operatorname{lng}=$ en\&nrm=iso >. Acesso em 02 Nov. 2017.

VILELA, Elaine Morelato; MENDES, Iranilde José Messias. Interdisciplinaridade e saúde: estudo bibliográfico. Rev. Latino-Am. Enfermagem, Ribeirão Preto, v. 11, n. 4, p. 525-531, Aug. 2003. Disponível em <http://www.scielo.br/scielo.php?script=sci_arttext\&pid=S0104$11692003000400016 \& \operatorname{lng}=$ en\&nrm=iso $>$. Acesso em 03 Nov. 2017. 